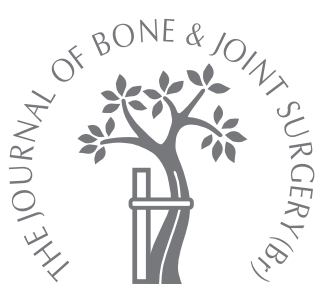

N. S. Kalson, P. D. Gikas, W. Aston, J. Miles, G. Blunn, R. Pollock, J. Skinner, T. W. R. Briggs, S. R. Cannon

From the Royal National Orthopaedic Hospital, Stanmore, United Kingdom

N. S. Kalson, BSc (Hons) Medical Student

Medical School, The Stopford

Building, Manchester University,

Oxford Road, Manchester

M13 9PT, UK.

P. D. Gikas, MBBS, MRCS,

Academic Clinical Fellow

W. Aston, FRCS (Orth),

Consultant Orthopaedic Surgeon

J. Miles, FRCS (Orth)

Consultant Orthopaedic Surgeon

R. Pollock, BSc (Hons), MBBS,

FRCS (Eng), FRCS (Tr \& Orth)

Consultant Orthopaedic Surgeon

I. Skinner, MBBS, FRCS (Eng)

FRCS (Tr \& Orth), Consultant

Orthopaedic Surgeon

S. R. Cannon, MA, MChOrth,

FRCS, Consultant Orthopaedic

Surgeon

Royal National Orthopaedic

Hospital, Brockley Hill, Stanmore, Middlesex HA7 4LP, UK.

- G. Blunn, PhD, Professor of Biomechanical Engineering

T.W. R. Briggs, MChOrth, FRCS

(Ed), FRCS (Eng), Professor of

Orthopaedic Surgery

Institute of Orthopaedic and

Musculoskeletal Science

University College of London,

London, UK.

Correspondence should be sent to $\mathrm{Mr} \mathrm{N}$. S. Kalson; e-mail: nickkalson@gmail.com

(C)2010 British Editorial Society of Bone and Joint Surgery doi:10.1302/0301-620X.92B8. $23682 \$ 2.00$

$J$ Bone Joint Surg $[\mathrm{Br}]$

2010;92-B:1134-7.

Received 13 October 2009;

Accepted after revision 14 April

2010

\title{
Custom-made endoprostheses for the femoral amputation stump
}

\author{
AN ALTERNATIVE TO HIP DISARTICULATION IN TUMOUR \\ SURGERY
}

\begin{abstract}
Disarticulation of the hip in patients with high-grade tumours in the upper thigh results in significant morbidity. In patients with no disease of the proximal soft tissue a femoral stump may be preserved, leaving a fulcrum for movement and weight-bearing. We reviewed nine patients in whom the oncological decision would normally be to disarticulate, but who were treated by implantation of an endoprosthesis in order to create a functioning femoral stump. The surgery was undertaken for chondrosarcoma in four patients, pleomorphic sarcoma in three, osteosarcoma in one and fibrous dysplasia in one. At follow-up at a mean of 80 months (34 to 132), seven patients were alive and free from disease, one had died from lung metastases and another from a myocardial infarction. The mean functional outcome assessment was 50 (musculoskeletal tumor society), 50 and 60 (physical and mental Shortform 36 scores).

Implantation of an endoprosthesis into the stump in carefully selected patients allows fitting of an above-knee prosthesis and improves wellbeing and the functional outcome.
\end{abstract}

For tumours of the thigh, limb-saving surgery results in a better functional and psychological outcome than an ablative procedure. ${ }^{1,2}$ However, despite improvements in imaging, patient selection, surgery, chemotherapy and radiotherapy techniques, limbsaving surgery may not be possible when there is extensive involvement of critical structures such as the femur, the neurovascular bundles or the musculature. ${ }^{3,4}$ In these rare cases a more extensive operation is required, and disarticulation through the hip may be necessary. When disease is more proximal, affecting pelvic structures, a hindquarter amputation is needed. ${ }^{5}$

However, total loss of the limb may be avoided by preserving a femoral stump and implanting a custom-made endoprosthesis. ${ }^{6,7}$ Preservation of the stump is indicated when there is distal femoral disease involving both bone and soft tissue, and where the proximal femoral bone is involved but not the soft tissue in the upper thigh. Preservation requires soft-tissue cover with a flap. It aims to improve function by leaving a fulcrum for weight-bearing and allowing easy fitting of a standard above-knee prosthesis without compromising patient survival. We carried out a retrospective study of all patients treated with an endoprosthesis for the femoral stump at our institution.

\section{Patients and Methods}

Information was gathered from the case notes, the hospital databases and assessment as outpatients. The outcome was assessed using the System for Functional Evaluation of the American Musculoskeletal Tumor Society (MSTS) ${ }^{8}$ and the Short Form-36 (SF-36) questionaire. The mean outcome measures were rounded to the nearest $10 \%$.

Indications and patient selection. The indication for treatment with an endoprosthesis for the femoral stump was extensive bony disease proximally or extensive soft tissue or bony disease distally in the thigh, with no proximal soft-tissue disease, making limb salvage impossible; and for which the oncological decision would usually be disarticulation through the hip. Patients with disease of the hip joint or extending into the pelvis were treated with hindquarter amputation and were not included in this study. All patients underwent staging and investigation before operation to determine the extent of local and distant disease. No patients had known metastatic disease or lymph node involvement at the time of surgery. The prosthesis was custom-made (Stanmore Implants Worldwide, Centre for Biomedical Engineering, London, United Kingdom) and manufactured using computer-assisted design and manufacturing technology (Fig. 1). Its proximal end was either a prosthetic hip joint, 


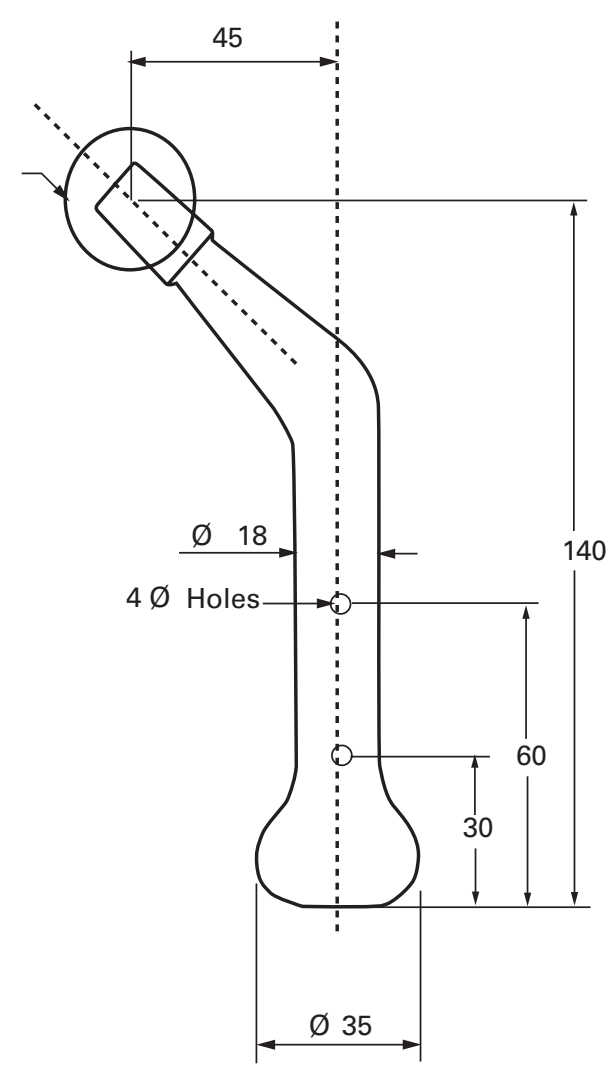

Fig. 1

Diagram of a custom-made femoral stump endoprosthesis. The proximal end articulates directly with the prosthetic acetabular component. In cases where preservation of the hip joint and proximal femur is allowed, the prosthesis fits directly into the remaining femoral stump. This prosthesis was produced for the second patient of the series; the measurements are in millimetres and $\varnothing$ indicates the diameter (illustration courtesy of Stanmore Implants Worldwide Ltd)

or in cases where there was no proximal femoral involvement, an intramedullary stem for insertion into the proximal femur. It was made of a titanium-cobalt-chromium alloy with a silver coating.

\section{Results}

Nine patients were identified (five male, four female), with a mean age at operation of 44 years (13 to 68; Table I). All had their surgery between 1997 and 2006 and were followed up for a mean of 80 months (34 to 132). The primary indication for surgery was chondrosarcoma in four, pleomorphic sarcoma in three, osteosarcoma in one and fibrous dysplasia in one. All the soft-tissue tumours were high grade, and the bone tumours were Enneking stage IIA. ${ }^{9}$ Of the tumours, seven were located in the distal femur and two in the thigh. The fibrous dysplasia arose from the distal femur. It had significant soft-tissue involvement causing gross deformation, and was not suitable for total femoral replacement. No patients had known malignant disease elsewhere at the time of operation.
Surgical technique and treatment. All surgery was performed by the senior author (SRC). The operative approach is by standard fishmouth flaps at the distal end of the residual limb which are extended proximally, lifting the whole of the vastus lateralis forward to finish as an anterolateral Watson-Jones-type approach to the hip joint. This allows exposure of the acetabulum without significant muscle damage, apart from dissection and division of the nerve to the tensor fascia lata. The acetabulum is either left without further reconstruction and a bipolar prosthesis inserted, or the hip is replaced using a constrained cemented component or a non-constrained component. The prosthesis is inserted and an anti-reduction ring screwed in to hold the femoral head in place. The custom-made femoral prosthesis must have a solid head and no modularity, so that it does not distract once inserted. Following insertion of the prosthesis the lateral musculature is repaired and a myoplasty performed over the prosthesis. The muscles themselves are not inserted into the prosthesis. In seven patients a custommade femoral amputation prosthesis was used primarily following resection of the tumour. The remaining two patients initially had a total femoral replacement, but this became infected and was converted to a femoral endoprosthesis. In six cases the hip joint was replaced (Figs 1 and 2) and in the remaining three an amputation prosthesis was cemented to a femoral stump.

Adjuvant therapy. All patients had appropriate adjuvant treatment administered under the supervision of an oncologist. In two patients neo-adjuvant treatment was given, three had adjuvant chemotherapy and two adjuvant radiotherapy. Outcome. All patients had wide margins of excision except for one patient with a malignant chondrosarcoma. There were no cases of recurrence at the time of review, and seven of the nine patients were alive and free of disease. Two patients had died, one due to myocardial infarction 11.5 years after operation, and the other from metastases to the lung after 8.5 years. The mean MSTS score was 50\% (35 to 66). The SF-36 was divided into physical and mental component scores; the mean physical component score was 50 (37 to 69 ) and the mean mental component score 60 (46 to 82). The combined physical and mental SF-36 scores were $60 \%$. The lowest MSTS, physical SF-36 and the second lowest mental SF-36 scores were recorded in the patient who required conversion to a disarticulation of the hip.

Complications. There were three major complications. A superficial wound infection occurred in one patient. It was treated successfully with antibiotics. Another had a deep infection which was treated by hip disarticulation. A further patient underwent revision of the prosthesis after 40 months because of aseptic loosening of the acetabular component.

\section{Discussion}

Tumours of the thigh that require amputation are extremely rare. Fewer than 30 disarticulations through the hip are performed each year in the United Kingdom. ${ }^{10}$ This is a devastating procedure for the patient, who is left both without a 


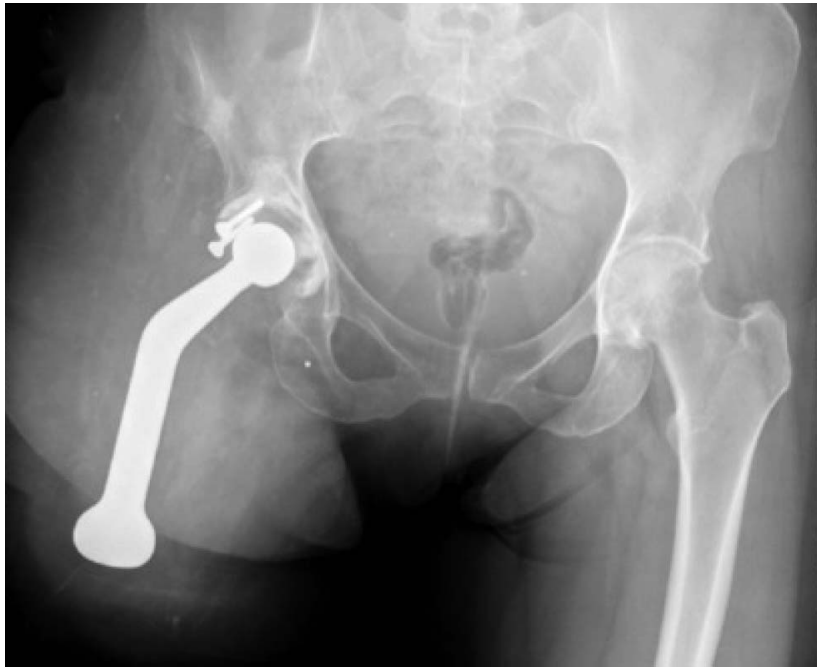

Fig. 2a

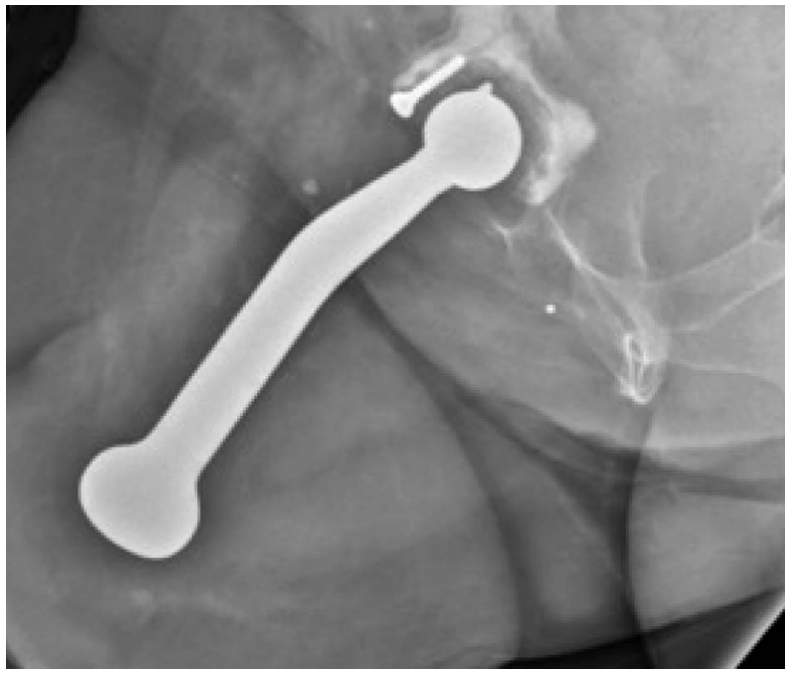

Fig. $2 b$

Anteroposterior a) and lateral b) radiographs of the right hip joint of a patient treated with a femoral stump endoprosthesis; 8.75 years postoperatively.

leg and without a fulcrum to move an artifical limb. Prostheses for patients with disarticulation of the hip or a higherlevel amputation have poor patient compliance. ${ }^{11-13}$ The patients have difficulty in walking and going up stairs, ${ }^{14}$ and expend a great deal more energy walking with the prosthesis than do able-bodied people. ${ }^{15}$ Amputees often walk with crutches, leading to painful overloading of the upper limb. ${ }^{14}$

Our patients had femoral disease with both bone and soft-tissue involvement, but with no soft-tissue disease in the upper thigh. This allowed preservation of an amputation stump, and eight of the nine survived their primary tumour, despite all the lesions being high grade. Only one death was caused by progression of tumour. Problems of protrusion of the stump through the skin have been encountered with femoral endoprostheses, and have been addressed by increasing the size of the load-bearing femoral-end surface. ${ }^{6}$ None of our patients suffered pain at the end of the stump.

Our patients were able to return home and begin outpatient rehabilitation at a mean of 12 days (6 to 35) after operation. Disarticulation of the hip or other ablative procedures can require a long hospital stay, ${ }^{16,17}$ most recently recorded as 30 days ( 11 to 65 ) in 15 patients. ${ }^{18}$

The use of varied outcome indicators in different studies and the rare occurrence of pathology requiring disarticulation of the hip makes comparison with treatment using a femoral endoprosthesis difficult. The mean functional outcome for hip disarticulation has been described as $53 \%$ in a series of 39 patients $^{3}$ and the mean MSTS as $61 \%$ in five patients. ${ }^{2}$ The nine patients treated with stump endoprostheses in our study had mean MSTS and SF-36 scores of $50 \%$ and $60 \%$, respectively. It is difficult to draw conclusions from these figures, but preservation of a stump, albeit with only limited functional movement, is likely to benefit the patient. Although sitting balance was not specifically assessed, it is likely that preservation of the stump improves sitting balance compared to disarticulation.

Most amputations of the lower limb in the developed world are performed in patients over the age of 60 for vascular disease. The majority of disarticulations of the hip and hindquarter amputations are for tumours and are carried out in the early decades of life. Such an extensive amputation in a young person can be extremely debilitating, and an improved functional outcome is desirable. Carefully selected patients can be provided with a functional above-knee amputation stump as a viable alternative to hip disarticulation. This reduces the severe cosmetic and functional limitations suffered by these patients compared to a disarticulation of the hip or hindquarter amputation, and improves the chance of a successful limb fitting. Although no direct comparison studies have been performed, it is likely that preservation of the hip joint will reduce energy expenditure, making mobilisation easier.

\section{Supplementary material}

$\because$ Tables showing i) the details of the diagnosis and the outcome in the nine patients and ii) the operative details for the nine patients treated with an amputation prosthesis is available with the online version of this article on our website at www.jbjs.org.uk

No benefits in any form have been received or will be received from a commercial party relatde directly or ndirectly to the subject of this article.

\section{References}

1. Nerubay J, Katznelson A, Tichler T, et al. Total femoral replacement. Clin Orthop 1988;229:143-8.

2. Renard AJ, Veth RP, Schreuder HW, et al. Function and complications after ablative and limb-salvage therapy in lower extremity sarcoma of bone. J Surg Oncol 2000;73:198-205 
3. Rougraff BT, Simon MA, KneisI JS, Greenberg DB, Mankin HJ. Limb salvage compared with amputation for osteosarcoma of the distal end of the femur: a longterm oncological, functional, and quality-of-life study. J Bone Joint Surg [Am] 1994;76-A:649-56.

4. Kawai A, Backus SI, Otis JC, Inoue H, Healey JH. Gait characteristics of patients after proximal femoral replacement for malignant bone tumour. J Bone Joint Surg [Br] 2000;82-B:666-9.

5. Clark MA, Thomas JM. Amputation for soft-tissue sarcoma. Lancet Oncol 2003;4:335-42.

6. Gosheger G, Hillmann A, RödI R, et al. Stump lengthening after hip disarticulation using a modular endoprosthesis in 5 patients. Acta Orthop Scand 2001;72:533-6.

7. Bottner F, Götze C, Koller A, et al. Creation of an above-the-knee amputation stump after hip disarticulation for severe periprosthetic infection and fracture: a report of two cases. J Bone Joint Surg [Am] 2005;87-A:410-13.

8. Enneking WF, Dunham W, Gebhardt MC, Malawar M, Pritchard DJ. A system for the functional evaluation of reconstructive procedures after surgical treatment of tumors of the musculoskeletal system. Clin Orthop 1993;286:241-6.

9. Enneking WF, Spanier SS, Goodman MA. A system for the surgical staging of musculoskeletal sarcoma: 1980. Clin Orthop 2003;415:4-18.
10. No authors listed. The Amputee Statistical Database for the United Kingdom. NHS National Services Scotland, 2006-2007:21. http://www.nasdab.co.uk/ pdf.pl?file=nasdab/news/Final_2006_07.pdf (date last accessed 15 April 2010).

11. Ferrapie AL, Brunel $\mathbf{P}$, Besse W, et al. Lower limb proximal amputation for a tumour: a retrospective study of 12 patients. Prosthet Orthot Int 2003;27:179-85.

12. Jain R, Grimer RJ, Carter SR, Tillman RM, Abudu AA. Outcome after disarticulation of the hip for sarcomas. Eur J Surg Oncol 2005;31:1025-8.

13. Fernández A, Formigo J. Are Canadian prostheses used? A long-term experience. Prosthet Orthot Int 2005;29:177-81.

14. Yari P, Dijkstra PU, Geertzen JH. Functional outcome of hip disarticulation and hemipelvectomy: a cross-sectional national descriptive study in the Netherlands. Clin Rehabil 2008;22:1127-33

15. Nowroozi F, Salvanelli ML, Gerber LH. Energy expenditure in hip disarticulation and hemipelvectomy amputees. Arch Phys Med Rehabil 1983;64:300-3.

16. Bruns J, Luessenhop S, Behrens $\mathbf{P}$. Cost analysis of three different surgical procedures for treatment of a pelvic tumour. Langenbecks Arch Surg 1998;383:359-63.

17. Zalavras CG, Rigopoulos N, AhImann E, Patzakis MJ. Hip disarticulation for severe lower extremity infections. Clin Orthop 2009;467:1721-6.

18. Daigeler A, Lehnhardt $\mathbf{M}$, Khadra $\mathbf{A}$, et al. Proximal major limb amputations: a retrospective analysis of 45 oncological cases. World J Surg Oncol 2009;7:15. 